\title{
Production of a PET//LDPE Laminate Using a Reversibly Crosslinking Packaging Adhesive and Recycling in a Small-Scale Technical Plant
}

\author{
Katharina M. A. Kaiser ${ }^{1,2, *(\mathbb{D})}$ and Tanja Ginzinger ${ }^{2}$ \\ 1 TUM School of Life Sciences Weihenstephan, Technical University of Munich, Weihenstephaner Steig 22, \\ 85354 Freising, Germany \\ 2 Fraunhofer Institute for Process Engineering and Packaging IVV, Giggenhauser Strasse 35, \\ 85354 Freising, Germany; tanja.ginzinger@ivv.fraunhofer.de \\ * Correspondence: katharina.kaiser.gap@googlemail.com
}

check for

updates

Citation: Kaiser, K.M.A.; Ginzinger, T. Production of a PET//LDPE Laminate Using a Reversibly Crosslinking Packaging Adhesive and Recycling in a Small-Scale Technical Plant. Recycling 2021, 6, 47. https://doi.org/10.3390/recycling60 30047

Academic Editor: Francesco Paolo La Mantia

Received: 19 May 2021

Accepted: 5 July 2021

Published: 13 July 2021

Publisher's Note: MDPI stays neutral with regard to jurisdictional claims in published maps and institutional affiliations.

Copyright: (c) 2021 by the authors. Licensee MDPI, Basel, Switzerland. This article is an open access article distributed under the terms and conditions of the Creative Commons Attribution (CC BY) license (https:// creativecommons.org/licenses/by/ $4.0 /)$.
Abstract: Multilayer packaging is an important part of the packaging market, but it is not recyclable with conventional methods since it is made of different thermodynamically immiscible materials. In this work, it was shown that it is possible to produce a PET//LDPE laminate in a pilot plant for lamination by using an adhesive consisting of maleimide- and furan-functionalized polyurethane prepolymers that cure through the Diels-Alder reaction. The material could then be delaminated in a small-scale recycling plant using a solvent-based recycling process by partially opening the Diels-Alder adducts through the influence of temperature. The PET and LDPE could be recovered without any adhesive residues before each material was regranulated, and in the case of the PE, a film was produced via cast film extrusion. The obtained PET granulate exhibited a slight, approximately $10 \%$, decrease in molecular weight. However, since small amounts of LDPE could not be separated, compatibilization would still be required here for further use of the material. The obtained LDPE film was characterized by means of infrared spectrometry, differential scanning calorimetry, tensile testing, determination of the melt index, and molecular weight. The film showed lower crosslinking than usual for LDPE recycling and exhibited good mechanical properties. In this work, it was thus shown that upscaling of the laminate production with the modified adhesive and also its recycling at the pilot plant scale is possible and thus could be an actual option for recycling multilayer packaging.

Keywords: multilayer packaging; recycling; reversibly crosslinking adhesive; Diels-Alder

\section{Introduction}

Our globally interconnected economic and trade system shapes today's food industry, causing long transport distances and storage times for food. A special role is played by multilayer packaging, in which different materials are combined in a layered structure, thus making it possible to create customized property profiles [1,2]. For example, defined barriers against oxygen and thus longer shelf life can be created; sealable packaging or certain optical properties can be produced, which is why multilayer packaging is an important part of the packaging market. However, since multilayer packaging is not recyclable due to its different components, new solutions are being sought [3]. Since replacement with monomaterials is often not easily possible and according to the European Plastics Strategy all packaging should be reusable or recyclable by 2030, other solutions have to be found [4].

To address this problem, there are several approaches that involve either processing the different materials together or separating them [3]. Joint processing yields blends that often have good mechanical properties only with the use of compatibilizers, and where the change in mechanical properties makes closed-loop recycling difficult to imagine [3,5-8].

In order to separate the different components for the recycling of multilayer packaging, polymers can be systematically dissolved out of mixed waste fractions by using selective 
solvents. This approach is suitable for a broad variety of mixed inputs, but the recovery of the polymer from the solvent can be quite energy consuming [3]. For the delamination of multilayer packaging, another approach to separate the different materials from each other, several approaches already exist, but these are often limited to certain structural designs, like packaging structures containing aluminum or the mechanism of delamination has not yet been elucidated [3,9-12]. One method for generating recyclability for a variety of multilayer packagings is to use reversibly crosslinking adhesives to produce delaminable packaging that can then be separated from each other by a solvent-based recycling process. Debondable adhesives can be based on different principles. These include adhesives filled with reactive fillers that are able to expand or heat up, causing delamination. Reversibly crosslinking adhesive systems are often based on the incorporation of Diels-Alder adducts into the network $[13,14]$. The Diels-Alder reaction is a $[4+2]$ cycloaddition in which a diene and a dienophile react reversibly. Here, the reaction between furan and maleimide groups is the most studied system [15-17]. In this study, as in two previous ones [18,19], a polyurethane adhesive containing Diels-Alder adducts was used to produce packaging laminates. These laminates could then be delaminated using a suitable solvent treatment and thus be separated for recycling.

In the first publication on this subject, typical material combinations used in packaging (PET//PE, PET//aluminum, PE//aluminum) were bonded on a laboratory scale by a packaging adhesive containing Diels-Alder adducts and also recycled on a laboratory scale. The adhesive here consisted of polyurethane-based isocyanate prepolymers functionalized with $\mathrm{N}$-(2-hydroxyethyl)maleimide and furfuryl alcohol. With the additional use of a crosslinker molecule with three furan groups, a crosslinked packaging adhesive could thus be prepared via the Diels-Alder reaction. The retro reaction in a heated solvent ensures that the adhesive becomes thermoplastic again and can thus be dissolved in a solventbased recycling process. Thus, composite separation takes place with no adhesive residues remaining on the composite materials [18].

In another publication, the adhesive formulation was adapted to replace the potentially carcinogenic furfuryl alcohol and the toxicologically unevaluated crosslinker molecule. This was done by using the noncarcinogenic furfurylamine and generating crosslinking via side chains of the polymers. By means of migration modeling, it was possible to check how far compliance with food regulations can be ensured when the adhesive is used in packaging [19].

Since the previous studies were only performed on a laboratory scale, the feasibility of this principle on a small technical scale will now be demonstrated in the present work. For this purpose, laminate production was scaled up to the pilot plant for lamination in order to produce 300 linear meters of a PET/ /LDPE laminate. The PET/ /LDPE laminate was selected for upscaling because it is one of the most relevant laminate types in the packaging market, frequently used in the packaging of snacks, meat, and dairy products and nonfood products [20], and the adhesive formulation showed good bonding in the laboratory tests for this packaging structure. After curing the adhesive, the 300 linear meters of the laminate can be delaminated in a small-scale recycling plant and the individual laminate components can then be reprocessed into granules or a film. A further aim of this work is to check to what extent sealing, as a typical processing step for packaging, influences the performance of the adhesive and what effects this could have.

\section{Materials and Methods}

\subsection{Preparation of the Adhesive}

The chemicals used to prepare the adhesive were purchased from different suppliers. For the production of the maleimide-functionalized prepolymer, 4,4'-methylenediphenyl diisocyanate (MDI) (98\%) was purchased from Alfa Aesar (Ward Hill, MA, USA) and used without further preparation, provided that dimer formation could be excluded Polypropylene glycol (Mw $=1000 \mathrm{~g} / \mathrm{mol}$ ) from Merck (Darmstadt, Germany) was used as the diol component and dried at reduced pressure and slightly increased temperature 
before use. To functionalize the maleimide prepolymer, a Diels-Alder and retro-DielsAlder reaction was used in a three-step process [21,22]. The solvent methyl ethyl ketone $(\geq 99.5 \%)$ was purchased from TH Geyer and, if necessary, dried with a molecular sieve $(4 \AA)$ to a $\mathrm{H}_{2} \mathrm{O}$ content $<50 \mathrm{mg} / \mathrm{kg}$ and stored under nitrogen $\left(\mathrm{H}_{2} \mathrm{O} \leq 50 \mathrm{mg} / \mathrm{kg}\right)$.

\subsubsection{Furan-Functionalized Prepolymer}

A schematic representation of the preparation of the furan-functionalized prepolymer is given in Figure 1.
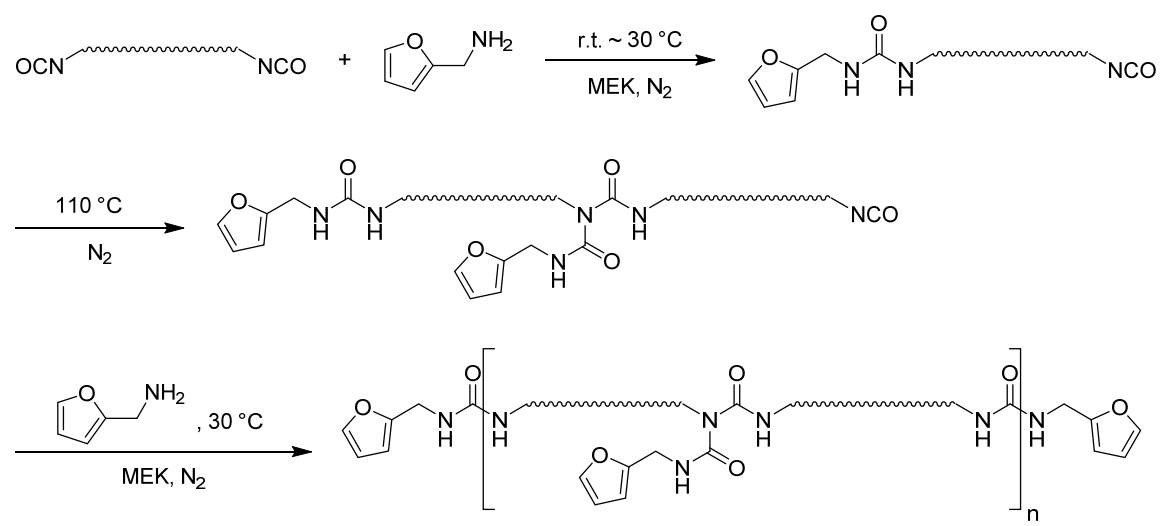

Figure 1. Reaction scheme for the preparation of the furan-functionalized prepolymer.

An amount of $575 \mathrm{~g}$ of isocyanate prepolymer (solids content, $401 \mathrm{~g}, 164 \mathrm{mmol}$, 3.00 NCO equiv.) was set under nitrogen in a three-necked flask equipped with a mechanical stirrer. Then, under vigorous stirring, $10.6 \mathrm{~g}$ (109 mmol, $10.1 \mathrm{mmol}, 1.00$ equiv.) of furfurylamine diluted in methyl ethyl ketone (MEK) was added in such a way that the temperature did not exceed $30^{\circ} \mathrm{C}$. After the reaction mixture was subsequently stirred for $30 \mathrm{~min}$ at room temperature, the oil bath was heated to $110{ }^{\circ} \mathrm{C}$ while evaporating the contained solvent. The mixture was kept at this temperature until the isocyanate band at $2264 \mathrm{~cm}^{-1}$ in the IR spectrum no longer decreased, indicating that all urea groups had reacted with isocyanate groups, while a yellow coloration of the mixture gradually appeared. By subsequently cooling the mixture to about $70{ }^{\circ} \mathrm{C}, 75 \mathrm{~mL}$ of MEK can be added, thus keeping the polymer stirrable. By adding $10.6 \mathrm{~g}(109 \mathrm{mmol}, 10.1 \mathrm{mmol}$, 1.00 equiv.) of furfurylamine in $37.5 \mathrm{~mL}$ of MEK, the reaction was terminated by functionalizing the remaining NCO groups.

The fully functionalized polymer yielded the finished product obtained in the form of a clear, yellowish, viscous polymer solution with a solids content of $80 \%$.

IR $\tilde{\mathrm{v}}=3315(\mathrm{br}), 2971(\mathrm{~m}), 2937(\mathrm{~m}), 2876(\mathrm{~m}), 1713(\mathrm{~s}), 1597(\mathrm{~m}), 1531(\mathrm{~s}), 1475(\mathrm{w})$, $1460(\mathrm{w}), 1413(\mathrm{~m}), 1372(\mathrm{~m}), 1308(\mathrm{~m}), 1219(\mathrm{~s}), 1169(\mathrm{~m}), 1066(\mathrm{~s}), 1018(\mathrm{~m}), 937(\mathrm{w}), 817$ (w) $767(w), 732(w), 630(m)$.

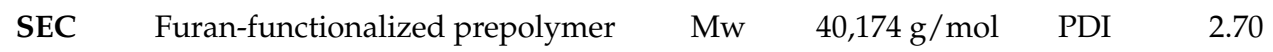

This polymerization was carried out in a similar way to the method of Du et al. [23].

\subsubsection{Maleimide-Functionalized Prepolymer}

A schematic representation of the preparation of the maleimide-functionalized prepolymer is given in Figure 2.

To prepare the maleimide-functionalized prepolymer, $135 \mathrm{~g}$ of MDI $(540 \mathrm{mmol}$, 3 equiv.) was first weighed in a three-necked flask flooded with $\mathrm{N}_{2}$ and heated to $50{ }^{\circ} \mathrm{C}$. Then, $360 \mathrm{~g}$ of polypropylene glycol 1000 ( $360 \mathrm{mmol}, 2.00$ equiv.) was added to the colorless liquid obtained, leading to an increase in the temperature of the reaction mixture due to the exothermic nature of the reaction. Once the temperature stopped increasing, the reaction mixture was heated to $80^{\circ} \mathrm{C}$ until the isocyanate band in the IR spectrum stopped 
decreasing, indicating an end to the reaction. An amount of $50.7 \mathrm{~g}$ (360 mmol, 2.00 equiv.) of $\mathrm{N}$-(2-hydroxyethyl)maleimide was then added to the mixture. The reaction was kept at $80{ }^{\circ} \mathrm{C}$ until the $\mathrm{NCO}$ signal disappeared. At the end, $140 \mathrm{~mL}$ of MEK was added for better handling.

3
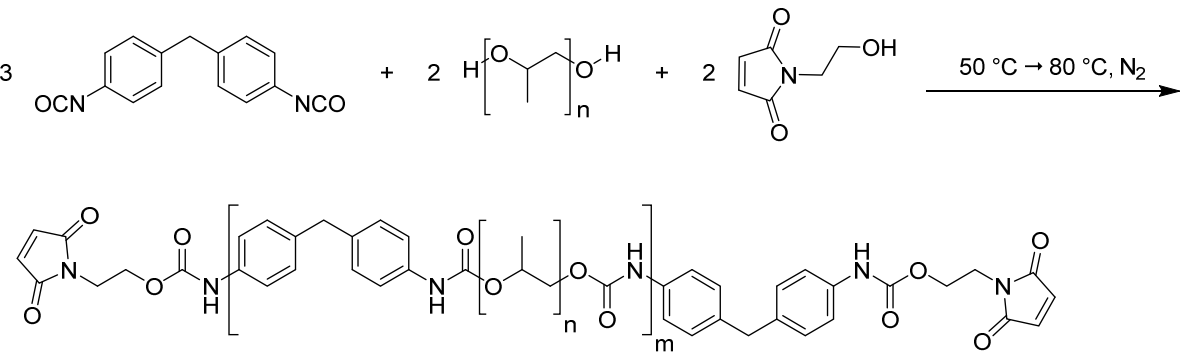

Figure 2. Reaction scheme for the preparation of the maleimide prepolymer.

The product was obtained in the form of a clear, yellow, and viscous polymer.

IR $\tilde{v}=3301$ (br), 2971 (m), 2868 (m), $1711(\mathrm{~s}), 1598$ (m), 1531 (s), 1451 (w), 1411 (m), 1373 (m), 1343 (w), 1309 (m), 1221 (s), 1076 (vs), 1017 (s), 926 (m), 821 (m), 768 (w), 696 (m).

$\begin{array}{lllll}\text { SEC } & \text { Maleimide-functionalized prepolymer } \quad \text { Mw } & 14,488 \mathrm{~g} / \mathrm{mol} & \text { PDI } & 1.81\end{array}$

\subsubsection{Preparation of the Adhesive Mixture}

An amount of $0.57 \mathrm{~kg}$ ( 0.31 mol of maleimide groups, 1.00 equiv.) of the maleimide prepolymer, dissolved in $140 \mathrm{~g}$ of $\mathrm{MEK}$, was weighed in a vial together with $0.73 \mathrm{~kg}$ ( $0.38 \mathrm{mmol}$ of furan groups, 1.00 equiv.) of the furan polymer, dissolved in $183 \mathrm{~g}$ of MEK. This mixture was diluted with another 2.7 L of MEK by stirring. In this way, a low-viscous, pale-yellow solution with $30 \%$ solids content was obtained.

\subsection{Production of the PET//PE Laminate}

The laminates were produced in a pilot plant for the lacquering and lamination of web materials by means of a roll-to-roll process. With the exception of the convection dryer, all components of the line were supplied by Jakob Weiß \& Söhne (Sinsheim, Germany). An overview of the individual elements of the system can be found in Figure 3. The facility has two corona devices for the pretreatment of the films, making in-line treatment of both LDPE and PET possible. The feed film was chosen to be the PET film ( $23 \mu \mathrm{m}$, Hostaphan ${ }^{\circledR}$ RNK), while the LDPE ( $45 \mu \mathrm{m}$, Hanita) film was chosen to be the lamination film. The strength of the corona treatment of the PET film was 300 watts $/ 5 \mathrm{~m} / \mathrm{min}$; that of the LDPE film was 600 watts $/ 5 \mathrm{~m} / \mathrm{min}$, which created a surface tension $>40 \mathrm{mN} / \mathrm{min}$ in both cases. The drying of the solvent was achieved with a convectional dryer made by the company Drytec Co. (Hamburg-Norderstedt, Germany) with $8000 \mathrm{~m}^{3} / \mathrm{h}$ of air circulation at $30{ }^{\circ} \mathrm{C}$. The adhesive systems were applied with a gravure roller system, with blunt pyramids having a depth of $0.203 \mathrm{~mm}$.

The layer thickness of the applied adhesive was determined by analyzing microtome cuts. For this purpose, $20 \mu \mathrm{m}$ thick microtome cuts were made with the Jung Autocut 2055 device from Leica Microsystems GmbH (Wetzlar, Germany), which were then analyzed with an optical microscope with lenses having $40 \times$ and $200 \times$ magnification.

The adhesive was cured (Figure 4$)$ ) at $23{ }^{\circ} \mathrm{C}$ over a period of 7 days.

IR (cured adhesive) $\tilde{\mathrm{v}}=3299$ (br), 2971 (m), $2872(\mathrm{~m}), 1724$ (s), 1702 (s), 1598 (m), 1532 (s), $1458(\mathrm{w}), 1413(\mathrm{~m}), 1374(\mathrm{~m}), 1342(\mathrm{w}), 1310(\mathrm{~m}), 1222(\mathrm{~s}), 1072(\mathrm{vs}), 1018(\mathrm{~s}), 930(\mathrm{~m})$, $853(\mathrm{~s}), 817(\mathrm{~m}), 767(\mathrm{~m}), 730(\mathrm{~m}), 716(\mathrm{~m})$.

\subsection{Recycling of the Laminate}

The solvent formulation used was developed by CreaCycle $\mathrm{GmbH}$ (Grevenbroich, Germany) based on the Hansen solubility parameters and taking into account other factors, 
such as the commercial availability of the ingredients and the risk to users and the environment [16]. It is a polar protic solvent, but the exact chemical compositions are property of CreaCycle $\mathrm{GmbH}$.



Figure 3. Schematic illustration of the used pilot plant for lacquering and lamination.

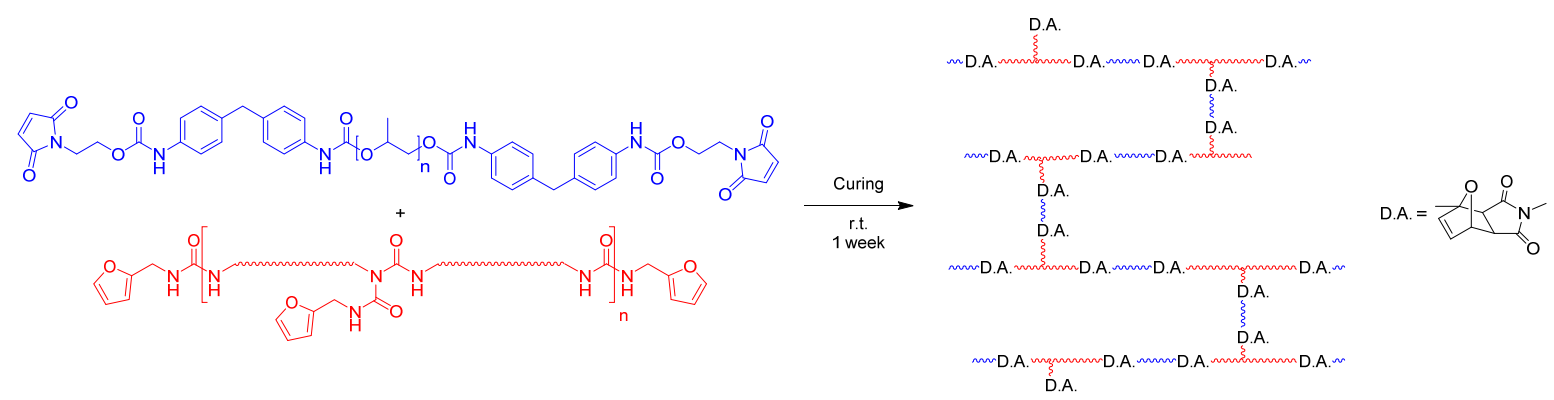

Figure 4. Crosslinking reaction of the two adhesive components during the curing process.

\subsubsection{Shredding of the Film}

The film was shredded using a Wanner Compact C13.20sv cutting mill from Wanner Technik $\mathrm{GmbH}$. The size of the flakes was predetermined by the insertion of a perforated screen with a hole diameter of $6 \mathrm{~mm}$. The flakes obtained had a size distribution of about $0.2 \mathrm{~cm}^{2}$ to about $0.7 \mathrm{~cm}^{2}$.

\subsubsection{Delamination of the PET//PE Film}

In order to open the Diels-Alder adducts in such a way that the adhesive can be removed (Figure 5), an amount of $10.3 \mathrm{~kg}$ of input material was treated in two batches in a dissolving kettle. For the first batch, $80 \mathrm{~kg}$ of solvent was first heated to $105^{\circ} \mathrm{C}$, and then $5.42 \mathrm{~kg}$ of the shredded material was added. The same was done for the second batch, with $70 \mathrm{~kg}$ of solvent and $4.88 \mathrm{~kg}$ of the material. The material was then stirred at this temperature for $20 \mathrm{~min}$ and then pumped out of the vessel. Density separation was then performed in a drum by skimming the floating fraction from the top and draining the sinking fraction from the bottom of the drum.

After pressing the materials to reduce the solvent content, the material was then prepared for further processing by predrying in the drying oven. 



Figure 5. Partial opening of Diels-Alder adducts under the recycling conditions.

\subsubsection{Degassing and Granulation}

Before the material was further processed, it was predried at $105{ }^{\circ} \mathrm{C}$ and $<50 \mathrm{mbar}$, which reduced the solvent content to $94 \%$ in the case of PE and $97 \%$ in the case of PET. Degassing and granulation were carried out with a corotating ZK $27 \mathrm{~T} \times 24 \mathrm{D}$ twin-screw extruder made by Collin Lab \& Pilot Solutions GmbH (Maitenbeth, Germany) with a length-to-diameter ratio of 24:1 and a screw speed of $150 \mathrm{rpm}$. The input material was fed in the compounder with a twin-screw feeder. To decrease the amount of residual solvent, two degassing units were installed into the extruder. For the treatment of LDPE and PET, different conditions were used.

For LDPE in the degassing zones, a pressure of 22-30 mbar/4.5-6 mbar was achieved. The strand die had a diameter of $3 \mathrm{~mm}$. Both a $315 \mu \mathrm{m}$ support screen and a $50 \mu \mathrm{m}$ screen were used for melt filtration, causing the melt pressure to increase between 76 and 180 bar. The machine data for the degassing and granulation of LDPE can be seen in Table 1.

Table 1. Machine data for LDPE degassing and granulation.

\begin{tabular}{ccccccccc}
\hline $\begin{array}{c}\text { Feeding } \\
\text { Unit }\end{array}$ & \multicolumn{9}{c}{ Temperature $\left({ }^{\circ} \mathbf{C}\right)$} \\
\hline $\mathbf{( k g} / \mathbf{h})$ & Zone 1 & Zone 2 & Degassing Zone 1 & Degassing Zone 2 & Zone 4 & Zone 5 & Zone 6 \\
\hline $0.5-0.6$ & 100 & 200 & 200 & 200 & 200 & 200 & 205 \\
\hline
\end{tabular}

For PET in the degassing zones, a pressure of $2.7 \mathrm{mbar} / 8.7 \mathrm{mbar}$ was achieved. The strand die had a diameter of $3 \mathrm{~mm}$, while the melt pressure was at around $12 \mathrm{mbar}$. The machine data for the degassing and granulation of PET can be seen in Table 2.

Table 2. Machine data for PET degassing and granulation.

\begin{tabular}{cccccccc}
\hline $\begin{array}{c}\text { Feeding } \\
\text { Unit }\end{array}$ & \multicolumn{7}{c}{ Temperature $\left({ }^{\circ} \mathrm{C}\right)$} \\
\hline $\mathbf{( k g / h )}$ & Zone 1 & Zone 2 & Degassing Zone 1 & Degassing Zone 2 & Zone 4 & Zone 5 & Zone 6 \\
\hline 0.4 & 140 & 260 & 243 & 243 & 243 & 243 & 243 \\
\hline
\end{tabular}

The strands were pelletized directly with a strand pelletizer from Collin Lab \& Pilot Solutions GmbH (Maitenbeth, Germany).

\subsubsection{Flat Film Extrusion}

The recycled LDPE film was produced on a coextrusion line for flat films from Collin Lab \& Pilot Solutions GmbH (Maitenbeth, Germany) using a clothes hanger distributor. The production was carried out at a constant haul-off speed of $1.8 \mathrm{~m} / \mathrm{min}$. The rotation speed of the screw was $65 \mathrm{rpm}$, and the target thickness of the film was $45 \mu \mathrm{m}$. The machine data for the cast film extrusion can be seen in Table 3 . 
Table 3. Machine data for LDPE cast film extrusion.

\begin{tabular}{ccccccc}
\hline Feeding Unit & \multicolumn{7}{c}{ Temperature $\left({ }^{\circ} \mathrm{C}\right)$} \\
\hline $\mathbf{( k g / h )}$ & Zone 1 & Zone 2 & Degassing Zone 1 & Degassing Zone 2 & Adapter & Chill Roll \\
\hline 1.2 & 30 & 180 & 220 & 240 & 240 & 60 \\
\hline
\end{tabular}

\subsection{Analytical Methods}

\subsubsection{Characterization by Infrared Spectroscopy}

Infrared spectroscopic measurements were recorded using an ATR measurement unit (Golden Gate, PerkinElmer, Shelton, CT, USA) and a Fourier-transform infrared spectrometer (FTIR) from PerkinElmer (Shelton, CT, USA). Ten scans were performed for each measurement with a wavelength range of 4000 to $600 \mathrm{~cm}^{-1}$. The corresponding software, Spektrum One, was used for evaluation. Since the contact pressure could not always be set quite the same when measuring the individual IR spectra, the intensities of the individual spectra differed somewhat. Therefore, the decreasing absorption bands of the maleimide group of the different spectra were not directly comparable. Quantification of the decrease in the intensity of the maleimide absorption band at $696 \mathrm{~cm}^{-1}$ was performed by relating it to the band of constant size at $767 \mathrm{~cm}^{-1}$. To do this, the intensities of the signal at $767 \mathrm{~cm}^{-1}$, setting a baseline from 791 to $743 \mathrm{~cm}^{-1}$, and the signal at $696 \mathrm{~cm}^{-1}$, setting a baseline from 702 to $667 \mathrm{~cm}^{-1}$, were determined in the individual absorption spectra.

The ratio of the intensities $\left(696: 767 \mathrm{~cm}^{-1}\right)$ between the two bands in the uncured spectrum was determined to be 0.8861 , and 0.0524 in the cured spectrum. The Degree of curing was therefore determined using Equation (1).

$$
\text { Degree of curing }=\frac{\text { ratio }\left(696 \mathrm{~cm}^{-1}: 767 \mathrm{~cm}^{-1}\right)}{(0.8861-0.0524)}
$$

\subsubsection{Determination of the Molecular Weight}

Size-exclusion chromatography (SEC) measurements were performed to determine the molecular weight of the adhesive polymers, PET and LDPE. In the case of the PET and the adhesive polymers, $40 \mu \mathrm{L}$ of a solution prepared from $50 \mathrm{mg}$ of sample and $10 \mathrm{~mL}$ of THF (in the case of adhesive polymers) or HFIP (in the case of PET) were injected using an ASI-100 Automate Sample Injector Unit from Dionex Corporation (Sunnyvale, CA, USA). To determine the molecular weight of the adhesive polymers, this procedure was modified slightly, and instead, $40 \mu \mathrm{L}$ of the recycling solution was injected directly after delamination. Calibration was performed using a polystyrene (THF) or poly(methyl methacrylate) (HFIP) standard of narrow molecular weight distribution (PSS, Polymer Standards Service, Mainz, Germany), and the measurement was performed at a flow rate of $1 \mathrm{~mL} \cdot \mathrm{min}^{-1}$ (Bischoff HPLC Compact Pump) according to DIN 55672-1 at $40{ }^{\circ} \mathrm{C}$. The separation column used was the GPC/SEC column SDV, linear M, $300 \times 8 \mathrm{~mm}, 5 \mu \mathrm{m}$, $100 \AA$ from PSS. The evaluation of the measurement results was carried out with the PL Cirrus GPC/SEC software (version 1.2). An error of $\pm 5 \%$ was assumed as the error for the Mw determined according to this protocol [24].

High-temperature SEC measurements of LDPE were performed in 1,2,3-trichlorobenzene. The oven system used was the PL-GPC 220 with an integrated DRI detector from Polymer Laboratories (Church Stretton, UK) coupled to a Dawn Heleos II multiangle static light scattering (MALS) detector from Wyatt Technology Corporation (Santa Barbara, CA, USA). Two PLgel Olexis separation columns, $300 \times 7.5 \mathrm{~mm}$, from Agilent Technologies (Santa Clara, CA, USA) were used for separation. The flow rate was $1.0 \mathrm{~mL} / \mathrm{min}$, and the set measurement temperature was $150^{\circ} \mathrm{C}$. Astra 7.0 software (Wyatt Tech Corp, Santa Barbara, CA, USA) was used for the interpretation of the results. 


\subsubsection{Headspace Gas Chromatography}

The experiments for determining the residual solvent content were performed on a Clarus 500-TRAP with a FID detector. The initial temperature was $50^{\circ} \mathrm{C}$ for $4 \mathrm{~min}$, and the sample was then heated to $320^{\circ} \mathrm{C}$ at $20^{\circ} \mathrm{C} / \mathrm{min}$ and held for $5 \mathrm{~min}$. The evaluation was carried out with Chromeleon Software.

\subsubsection{T-Peel Test}

T-peel tests were carried out to check the bond adhesion. These were performed on a Schenck Trebel universal testing machine type RM 50 from Bischoff Prüftechnik GmbH (Solingen, Germany). For the measurement, the laminate was cut into $15 \mathrm{~mm}$ wide strips perpendicular to the lamination direction. The measurement was carried out in such a way that there was an angle of $90^{\circ}$ between the separated strips and the unseparated part of the laminate. The measuring range was $60 \mathrm{~mm}$, whereby a measuring range of 5 and $60 \mathrm{~mm}$ was used for the evaluation of the measurement, provided that no substrate failure occurred.

The measuring speed was $50 \mathrm{~mm} / \mathrm{min}$. The evaluation was carried out with the Test\&Motion program of the company Doli Elektronik GmbH (Münsingen, Germany).

\subsubsection{Differential Scanning Calorimetry}

Thermal analyses were performed using a "DSC $3+$ " instrument manufactured by Mettler Toledo (Columbus, OH, USA). For all measurements, two heating runs were performed at a $\mathrm{N}_{2}$ purge gas rate of $20 \mathrm{~mL} / \mathrm{min}$ and constant heating and cooling rates of $10 \mathrm{~K} / \mathrm{min}$. The amount of sample weighed in was about $12 \mathrm{mg}$ each. Evaluation was performed with the STARe software from Mettler. The second heating run was used for evaluation in each case. The degree of crystallinity (Xcr) was estimated using Equation (2), assuming that the enthalpy of fusion of $100 \%$ crystalline $\mathrm{PE} \Delta \mathrm{H}_{100 \%}(\mathrm{PE})=293 \mathrm{~J} / \mathrm{g}$ was used and for PET $\Delta \mathrm{H}_{100 \%}(\mathrm{PET})=140 \mathrm{~J} / \mathrm{g}[25,26]$.

$$
X_{c r}=\frac{\Delta H_{f}}{\Delta H_{100 \%}} \cdot 100 \%
$$

\subsubsection{Determination of the Melt Flow Index (MFI)}

The MFI measurements for LDPE were carried out on a MeltFlow @on unit from Karg Industrietechnik (Krailling, Germany). The parameters set were in accordance with ASTM D 1238 , and the tests were carried out accordingly at $190^{\circ} \mathrm{C}$ and $2.16 \mathrm{~kg}$.

\subsubsection{Determination of the Viscosity of the Adhesive}

The viscosity of the prepared adhesive was determined in two different ways. The first method used to determine viscosity was according to ISO 2431-No4 with a VF2049-769 viscosity cup of TQC (Rotterdam, the Netherlands). With this method, the viscosity of adhesives can be determined by the time it takes for the liquid to flow out of the cup. In addition, viscosity was determined using an Anton Paar Physica MCR 301 rheometer from Anton Paar AG (Graz, Austria) with a plate-plate measuring system with a diameter of $25 \mathrm{~mm}$. The selected shear rate of the measurement was $501 \cdot \mathrm{s}^{-1}$ at a temperature of $23^{\circ} \mathrm{C}$. The measuring gap was $0.25 \mathrm{~mm}$, and the sample volume used was $200 \mu \mathrm{L}$.

This measuring system was also used to estimate the pot life based on DIN EN ISO 10364. The pot life was defined as the time in which the viscosity doubles, as this would probably no longer lead to a streak-free application. For this purpose, measurements of the sample were performed at the beginning at intervals of $2 \mathrm{~h}$ and then twice a day.

\subsubsection{Tensile Test}

The mechanical properties of the films were tested on a Z005 tensile testing machine (AllroundLine) from Zwick $\mathrm{GmbH} \& \mathrm{Co} . \mathrm{KG}$ at $23{ }^{\circ} \mathrm{C}$ and $50 \% \mathrm{RH}$ according to DIN EN 
ISO 527-1. For this purpose, at least 5 strips of each film were prepared in the machine direction with a defined width of $15 \mathrm{~mm}$.

\subsubsection{Sealing Test}

In order to check the effect of temperature on the adhesive during sealing, sealing tests were carried out with an HSG-CC heat sealer from Brugger Feinmechanik GmbH (Munich, Germany). For this purpose, $15 \mathrm{~mm}$ wide test strips were first cut from the laminate perpendicular to the laminate direction, as in the T-peel test, so that the tabs of the LDPE and PET could subsequently be used to perform the T-peel test. The test strips were inserted individually into the sealing device so that the sealing jaws hit the laminate in such a way that the application edge of the adhesive was affected. The parameters set in the sealing device were $160^{\circ} \mathrm{C}, 1 \mathrm{~s}$, and 80 bar.

\section{Results and Discussion}

\subsection{Preparation of the Laminate}

As in a previous publication, the formulation was chosen in such a way that no carcinogenic, mutagenic, or reprotoxic chemicals were required to functionalize the prepolymers; moreover, no crosslinking molecule was necessary [19]. This was achieved by the fact that the furan-functionalized prepolymer contains furan side chains and thus, on average, three functional groups. The maleimide prepolymer, on the other hand, is linear (see Figure 6)). When formulating the two prepolymers in MEK, care was taken to ensure that the physical properties of the adhesive were similar to the parameters of commercial adhesives in order to guarantee an unproblematic and even application of the adhesive in the laminating process. Therefore, a solids content of $30 \%$ was selected, at which, according to ISO 2432-No4, the adhesive needed $19.6 \mathrm{~s}$, which was in the same order of magnitude as the times commercial solvent-based packaging adhesives needed. On the rheometer, this corresponded to a viscosity of $40 \mathrm{~Pa} \cdot \mathrm{s}$ at a shear rate of $501 \cdot \mathrm{s}^{-1}$. The pot life of the adhesive was determined by the change in viscosity of the $30 \%$ solution over time due to the crosslinking of the adhesive to about $24 \mathrm{~h}$.



Figure 6. Overview of the individual steps in laminate production. Step 1 represents the production of the adhesive, step 2 the lamination of the PET film with the LDPE film, and step 3 the curing of the adhesive.

To ensure that the stresses that affected the laminate in the laminating machine did not lead to problems during winding, care was taken that the adhesive was sufficiently tacky. Therefore, polypropylene glycol was used as the diol component for the maleimide 
prepolymer, which made the prepolymer a viscous liquid that led to tackiness of the formulation.

By processing this adhesive on the laminating line described in Materials and Methods, 300 linear meters of a PET/ / LDPE laminate could be produced. Using microtome sectioning, the thickness of the adhesive was determined to be $6.5 \mu \mathrm{m}$ (compare Figure 7), thus slightly exceeding the typical layer thicknesses of conventional packaging adhesives, which were around 2-5 $\mu \mathrm{m}$ [27].

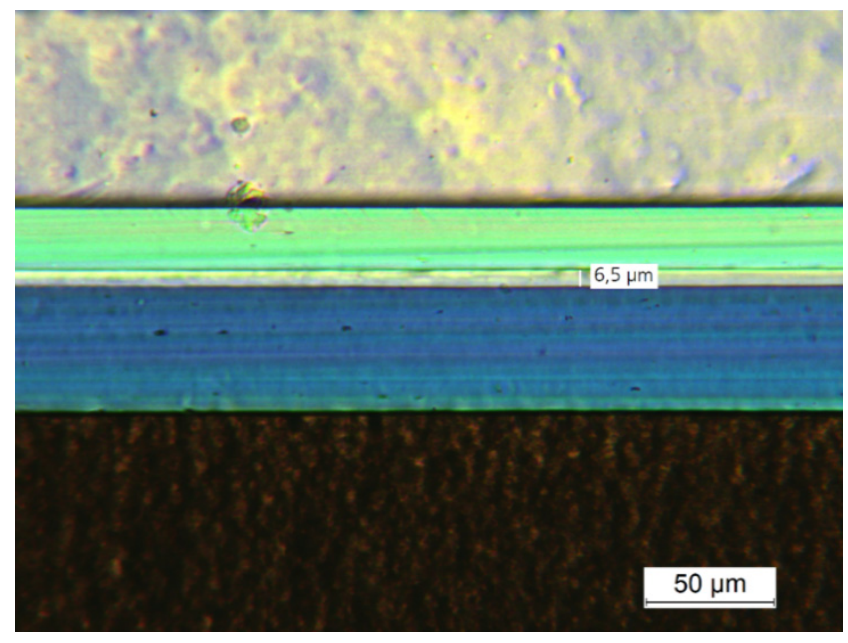

Figure 7. Microtome cut of the produced PET-PE laminate. The green material layer represents the PET film, the blue one the LDPE film.

The curing process of the adhesive, the last step of the preparation of the laminate, was followed by infrared spectroscopy. Here, the decrease. of the ring deformation mode of the maleimide group at $696 \mathrm{~cm}^{-1}$ could be followed [28]. It was determined that $73.8 \%$ of the isocyanate groups had already reacted after 1 day, and $88.3 \%$ after 2 days. Since the isocyanate band disappeared completely after 7 days, it was assumed that after this time had elapsed, the Diels-Alder reaction was completed (see Figure 8).

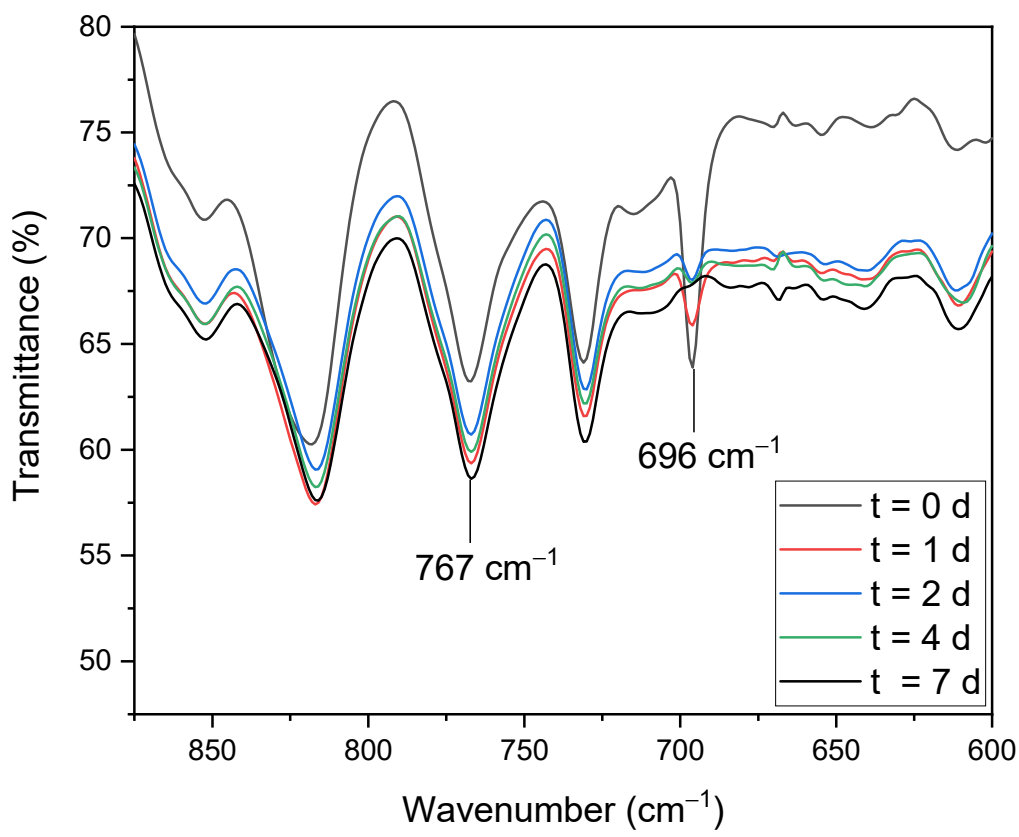

Figure 8. Decrease of the ring deformation mode of the maleimide group at $696 \mathrm{~cm}^{-1}$ over a time period of 7 days. 
The bonding of the PET//LDPE laminate was tested using the T-peel test (see Figure 9). It was found that each of the five test strips had a substrate failure of the PET, which implies that the bond was stronger than the cohesion of the PET. This means that the bonding in this case was stronger than in the previous publication [19], although the same adhesive formulation and the same adhesive layer thickness were chosen. However, in contrast to manual lamination, machine lamination allowed an even application of the adhesive and lamination without any air bubbles. At $6.5 \mu \mathrm{m}$, the application of the adhesive was slightly thicker than in most commercial cases of packaging laminates, where the adhesive layer thickness is usually around $3 \mu \mathrm{m}$ [27]. With a lower adhesive layer thickness, a decrease in bond adhesion was also to be expected. However, since in many cases an adhesive strength of $2 \mathrm{~N} / 15 \mathrm{~mm}$ would already be sufficient, it should also be possible to use a thinner adhesive layer.

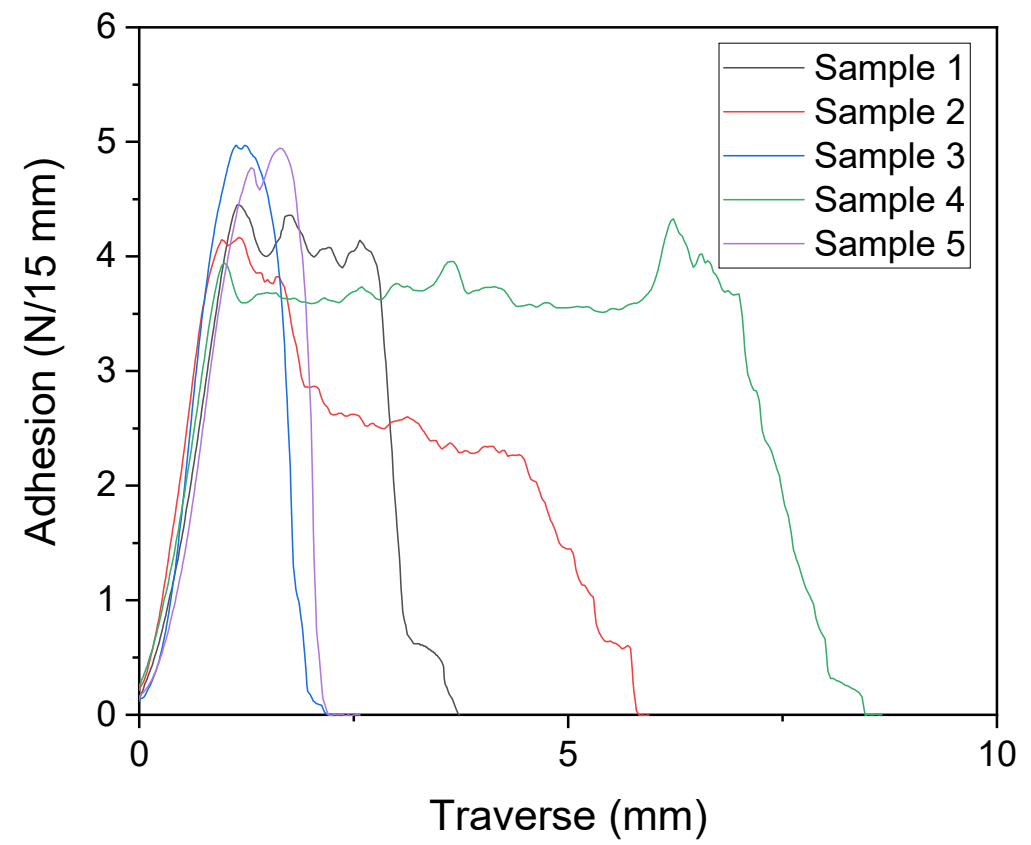

Figure 9. T-peel test results of the cured PET//LDPE laminate.

\subsection{Behavior of the Adhesive during the Sealing Process}

Since a mere laminate does not yet constitute packaging, it must be converted into a packaging in a thermomechanical processing step such as sealing to form a pouch or thermoforming to form a tray. For the adhesive, however, this means that it has to withstand thermal stress. Therefore, the influence of short-term high-temperature exposure of sealing jaws on the crosslinking of the adhesive was examined here. The conditions chosen for this were a temperature of $160{ }^{\circ} \mathrm{C}$ with a sealing time of $1 \mathrm{~s}$, which can be considered typical sealing conditions for LDPE [29].

It can be seen that the ring deformation mode of the maleimide group at $696 \mathrm{~cm}^{-1}$ reappeared (see Figure S1). From the ratio of this absorption band, it was possible to estimate that about $62 \%$ of the Diels-Alder adducts had undergone the retro-Diels-Alder reaction. By recording another IR spectrum 10 days after the sample was sealed, it was shown that the adhesive was re-crosslinking. According to the literature, it would be expected that the re-crosslinking does not take place completely since residual amines can react with the maleimide groups at $70^{\circ} \mathrm{C}$ and above in a Michael addition [30,31].

However, since the degree of crosslinking is determined via the absorption band of the maleimide group, this effect cannot be detected here. Since the residual content of furfurylamine was only about $15 \mathrm{ppm}$ and the functionalization of the NCO groups was complete, it can be expected that the maleimide was not blocked in relevant amounts [19]. 
In order to test the influence of the partial opening of the Diels-Alder adducts by the temperature effect of the sealing test on the bond adhesion of the laminate, a T-peel test was performed directly after temperature exposure by the sealing jaws. Figure 10 shows the measurement curves of the T-peel tests.

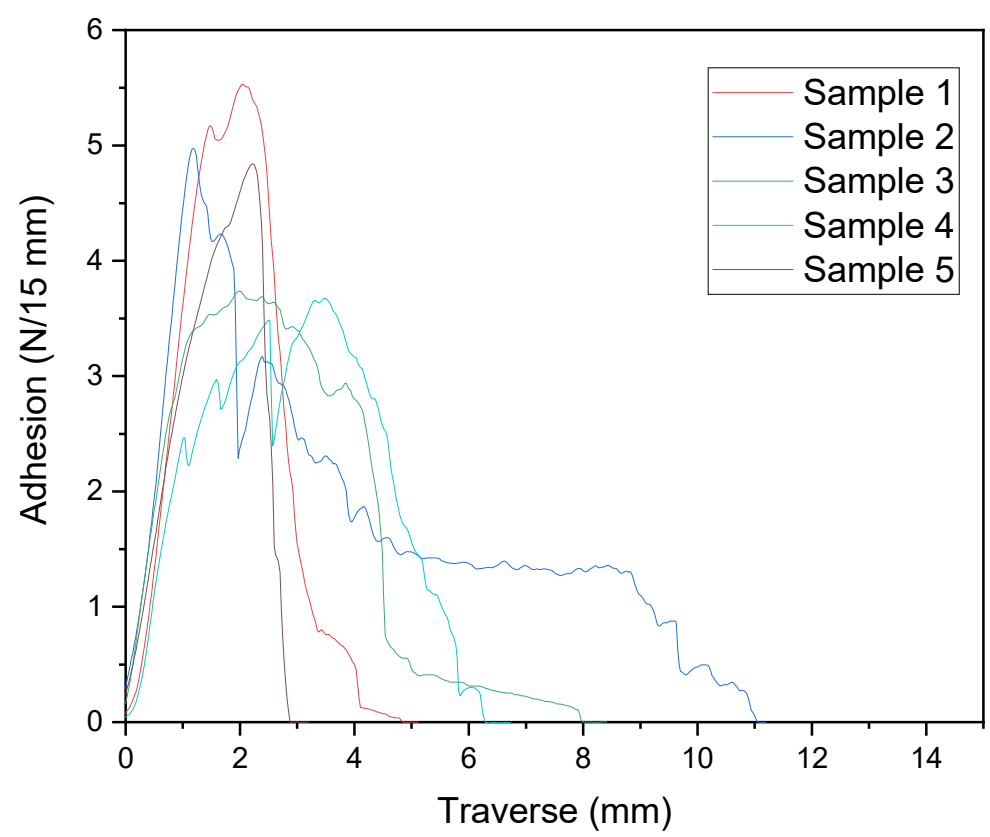

Figure 10. T-peel test results of PET//LDPE laminate after temperature exposure at $160{ }^{\circ} \mathrm{C}$ for $1 \mathrm{~s}$ in the sealing machine.

Here, too, as in the T-peel tests of the nonsealed samples, an immediate substrate failure of the PET film occurred. This means that even with a reduced crosslink density of the adhesive after the sealing treatment, there is still sufficient crosslink density in the adhesive to ensure cohesion in the adhesive. This shows that even directly after thermal processing of the packaging, laminate adhesion is still present, which is why there is no risk of unwanted delamination in this step.

\subsection{Recycling of the PET//LDPE Laminate in a Small-Scale Technical Plant}

The individual steps of the recycling process are shown in Figure 11 and include six steps: (1) shredding of the film, (2) solvent treatment, (3) density separation, (4) predrying of the material, (5) degassing and granulation, and (6) extrusion of the recycled film.

\subsubsection{Step 1-Shredding}

Shredding provided a size distribution of about $0.2 \mathrm{~cm}^{2}$ to about $0.7 \mathrm{~cm}^{2}$, which was a smaller size than in previous publications, in which the dimensions were $1 \times 1 \mathrm{~cm}$. This is because the material has to be fed into the extruder in step 5, and this is easier to carry out with smaller flake sizes. The smaller flake size also reduces the time needed for solvent treatment, as the dissolution of the adhesive proceeds via the cut edges of the flakes, and the area of the cut edges increases with decreasing flake size. However, the size distribution of the flakes influences the duration of delamination.

\subsubsection{Step 2-Solvent Treatment of the Shredded Material}

Step 2, the dissolving step itself was carried out for $20 \mathrm{~min}$ at $105^{\circ} \mathrm{C}$ in a stainless steel vessel with a capacity of $100 \mathrm{~L}$. The ratio between film and solvent was chosen so that the shredded films were completely covered with solvent.

In contrast to previous publications, in which laboratory-scale experiments were carried out, the solvent used in this pilot plant experiment was not dimethyl sulfoxide but an optimized proprietary CreaSolv ${ }^{\circledR}$ solvent from CreaCycle GmbH. Like DMSO, this 
solvent has the property of being able to dissolve the polymers of the adhesive, but it does not have the disadvantages associated with DMSO, such as the smell or the freezing point close to room temperature. Instead, it is characterized by a high flash point, which allows convenient and economical transport and storage, and a comparatively low evaporation enthalpy, which is favorable for solvent recycling.
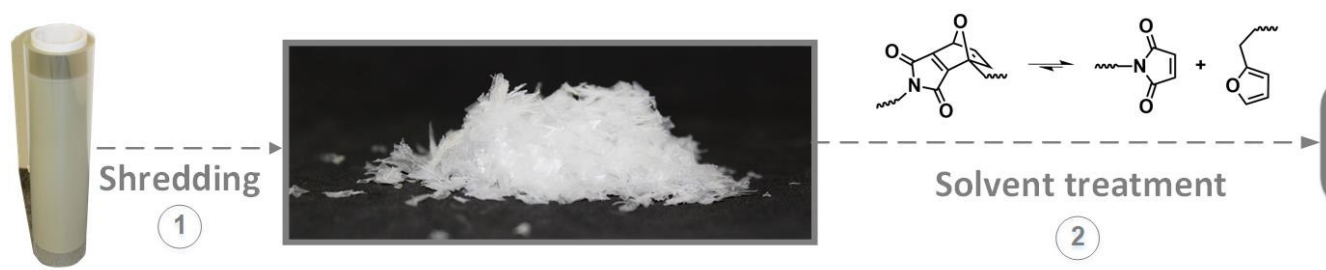

\section{Delaminated films in solvent}


Figure 11. Overview of the individual steps of the recycling process.

The time required for delamination in the solvent was determined in advance by laboratory-scale tests in which the time required for the delamination of particularly large flakes was determined in a dissolution test. In order to estimate the influence of a treatment time of $20 \mathrm{~min}$ at $105^{\circ} \mathrm{C}$, a test strip of the cured adhesive was exposed to these conditions in the drying oven, and an IR spectrum was recorded immediately afterwards. Here, too, as after treatment with the sealing device, an increase in intensity of the maleimide absorption band can be observed. From the ratio of the maleimide absorption band to the band at $767 \mathrm{~cm}^{-1}$ compared with the ratio of the two bands in the uncured adhesive, we found that $35 \%$ of all Diels-Alder adducts had undergone the retro reaction and were therefore present in their opened form (see Figure S2). Since the adhesive formulation was 
chosen in such a way that each furan-functionalized prepolymer carried on average three functional groups, the opening of $35 \%$ of the adducts should also be sufficient to cancel the crosslinking of the adhesive. In this IR experiment, however, the adhesive was heated to $105^{\circ} \mathrm{C}$ in the oven, whereas in the actual recycling experiment, the temperature effect would take place in the presence of a solvent. In the solvent, once an adduct is opened, the functional groups can be surrounded by a solvate shell and thus washed away from the interlayer of the composite, becoming less likely due to dilution. It is also conceivable that the kinetics of the retro-Diels-Alder reaction could be affected since it is known that the solvent has an influence on the kinetics of the Diels-Alder reaction [17,31-35]. However, Widstrom et al. [36] performed studies on the kinetics of the retro-Diels-Alder reaction between a maleimide and furan in different solvents and could not demonstrate any influence. Therefore, it could be assumed that in the present case, there was also no influence on the kinetics of the retro-Diels-Alder reaction due to the solvent. However, it must be taken into account that the retro-Diels-Alder reaction does not necessarily take place in the solvated state, since the adhesive is crosslinked and thus initially not soluble, and is also embedded between layers of LDPE and PET. It can therefore be assumed that the retro-Diels-Alder reaction takes place to a relevant extent without interactions with the solvent or at most in a swollen state. A reliable statement on how the solvent influences the kinetics of the reaction and the mass transfer cannot be made without further investigations. The partial opening of the adducts can also be demonstrated by SEC measurements. The adhesive molecules in the recycling solvent directly after completion of the dissolution step show an elution peak in the SEC measurement, with Mw 44,470 g/mol. If the two prepolymers are freshly dissolved together and a SEC measurement is performed, an elution peak resulting from the superposition of the two prepolymers is shown, with $\mathrm{Mw}$ of $26,916 \mathrm{~g} / \mathrm{mol}$. This would indicate that more than one in three Diels-Alder adducts would be open. However, these two values can only be compared with a limited extent since a branched polymer is obtained due to the incomplete openings of the adducts, and branched molecules have smaller radii of gyration, and thus, smaller molar masses are determined than are actually present [37]. Therefore, estimation by IR spectroscopy seems to provide a more reliable result.

IR spectra were recorded on both sides of the dried flakes to check whether the adhesive could be completely removed. For this purpose, especially large flakes were selected from a sample of both fractions, as these have longer delamination times and should therefore be most likely to have adhesive residues on larger flakes. Figure 12a shows a spectrum of the original LDPE film and also spectra taken on both sides of a delaminated LDPE film. It can be seen that on both sides of the recovered LDPE film, there is no evidence of adhesive even where the most intense bands of adhesive at 1711, 1531, and $1072 \mathrm{~cm}^{-1}$ would be expected. The same can be observed with the spectra of PET (Figure 12b). Therefore, it can be assumed that there is no residue of the adhesive on the surfaces of the films.

\subsubsection{Step 3-Density Separation}

Step 3 of the recycling process is the density separation. Therefore, subsequent to the solvent treatment, the flakes and the solvent were pumped into a barrel where a floating layer of LDPE and a sunken fraction of PET could be identified. Before the LDPE fraction was skimmed off with a sieve, the LDPE layer was stirred several times to give PET flakes, which might have been lying on the LDPE flakes and were thus prevented from sinking, the opportunity to sink. The sink fraction was then removed via an outlet at the bottom of the barrel and separated from the solvent. Both the floating and the sinking fractions were mechanically pressed out to reduce the solvent content.

In order to evaluate the effectiveness of the composite separation, the mass fractions of the floating, sinking, and solvent fractions; their experimentally determined solvent content; and the solids content calculated from them are given in Table 4. 


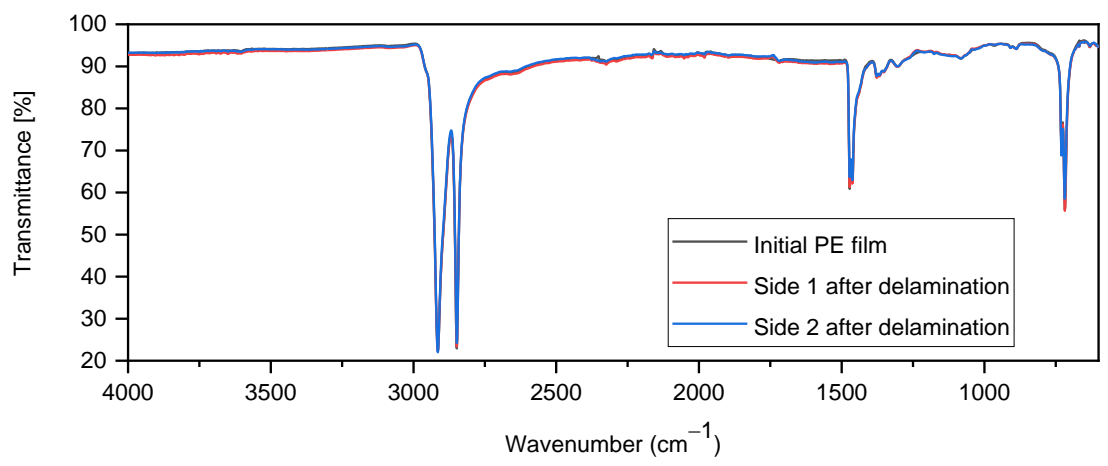

(a)

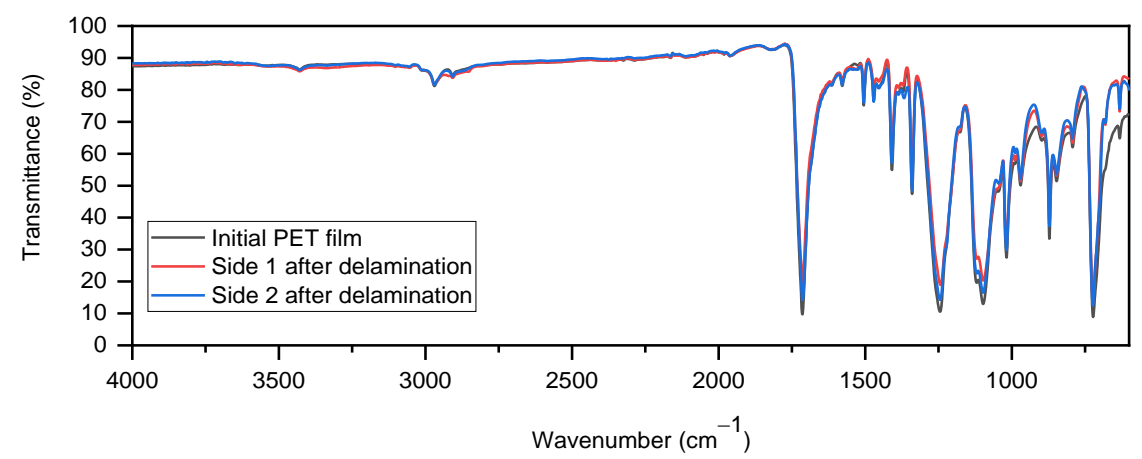

(b)

Figure 12. IR spectra of both sides of a delaminated film ((a) PE, (b) PET) and the respective starting film as reference.

Table 4. Overview of the quantities of the floating and sinking fractions obtained after density separation and the solvent fraction containing the adhesive.

\begin{tabular}{lccccc}
\hline & Quantity & Solvent Content & Solid Content & Ratio of the Solid Content & Theoretical Ratio \\
\hline & $\mathbf{k g}$ & $\mathbf{( \% )}$ & $\mathbf{( k g )}$ & & \\
\hline Floating fraction & 6.8 & 32.1 & 4.6 & 5.8 & 5.1 \\
Sinking fraction & 3.7 & 17.3 & 3.0 & 1 & 3.9 \\
Solvent fraction & 146 & 99.4 & 0.8 & 1 & 1 \\
\hline
\end{tabular}

The solids content of the solvent can be attributed to the dissolved adhesive. The theoretical ratio of the fractions to each other was calculated on the basis of the layer thicknesses of PET, LDPE, and the adhesive and their densities. Comparing the ratio of the obtained quantity fractions with the theoretically expected ratio, it was noticeable that the actually obtained quantity of LDPE exceeded the theoretically expected one, while the actually obtained quantity of PET was lower than expected. This would indicate that a relatively high proportion of PET must be contained in the floating fraction.

To validate this, the LDPE content in both the floating and sinking fractions was dissolved out with a selective solvent. It was found that the floating fraction, which consisted of PE, still contained 3\% PET. However, the PET fraction still contained 15\% LDPE. This contradicts the estimation based on the theoretical mass fractions. The reason for the incorrect estimation could be, for example, that it is difficult to take a representative, homogeneous sample to determine the solvent content.

The reason for the remaining PET in the LDPE floating fraction could be air bubbles adhering to the PET or PET flakes lying on LDPE flakes. The LDPE content in PET can also 
be partly explained by the LDPE flakes being prevented from rising by the PET flakes. The handling of the density separation may also have caused LDPE to enter the PET fraction, because when the PET fraction was drained off at the bottom of the barrel, LDPE was also carried from the floating fraction into the sinking fraction. These two problems should be reduced by cyclonic separation equipment, which is specifically designed for density separation of materials. Nevertheless, it cannot be excluded that a certain amount of LDPE was not yet delaminated from the PET, which could mean that the duration of the solvent treatment would still have to be extended.

\subsubsection{Step 4, 5, and 6-Drying Granulation and Flat Film Extrusion}

The two fractions obtained are predried before they are further processed in the extruders, whereby a solids content of $94 \%$ could be achieved for the PE floating fraction and $97 \%$ for the PET sinking fraction. This reduces the influence of the solvent on the extrusion and enables a low residual solvent content. During the pelletizing of the LDPE, a melt screen could be installed in the extruder to remove the remaining PET. Since the LDPE has a lower melting point than PET, it was not possible to remove the LDPE residue during PET pelletizing.

To remove the solvent from both materials, a vacuum was applied in the extruder for degassing. In this way, LDPE granulate with a residual solvent content of $219 \mathrm{ppm}$ and PET granulate with a residual solvent content of $4 \mathrm{ppm}$ were obtained. The LDPE granulates were extruded into a film with a target thickness of $45 \mu \mathrm{m}$ like the initial film.

\subsubsection{Recovery of the Adhesive and the Solvent}

A recovery of the adhesive from the solution would be theoretically conceivable and could be performed, for example, by precipitation from solution or by distillation. In practice, however, such a procedure would not be very practical. The reason for this is that the equilibrium of the Diels-Alder reaction at room temperature would shift on the side of the adduct, and the adhesive would thus crosslink again. If the process were to be used for post-consumer packaging, the solution would contain printing ink and other impurities, such as packaging residues in addition to the adhesive. This would make recovery of the adhesive even more impractical.

The adhesive solution obtained through the recycling process is also not suitable for the direct production of a new laminate for various reasons. One obvious reason is that a solids content of $0.6 \%$ is far too low, and as in the production of the laminate, a solids content of $20 \%-50 \%$ would rather be necessary. However, even if this solids content could be achieved by concentrating the solution, the solution would not be suitable for lamination, as low-boiling solvents such as ethyl acetate or MEK must be used for this purpose.

Therefore, the solution is distilled to recover the solvent, but the adhesive would be discarded as a distillation residue.

For the process to be both ecologically sound and economical, it is necessary to recycle the solvent by distillation. Because the solvent has a low enthalpy of vaporization and a low vapor pressure at room temperature, recovery of the solvent is possible with relatively low energy consumption and low solvent losses.

\subsubsection{Characterization of the Recovered PE}

Both the LDPE regranulate and the recycled film are colorless but exhibit a slight haze. Figure 13 shows the IR spectra of LDPE after granulation and film extrusion with the spectrum of the initial film as a reference. It can be seen that some additional absorption bands appeared due to the extrusion processes. These were more intense in the spectrum of the recycled film than in the spectrum of the granulate since one more extrusion had to be performed for the film. At $1750 \mathrm{~cm}^{-1}$, a carbonyl absorption band can be observed, which indicates the presence of ketones or aldehydes and is typical for oxidative degradation processes in LDPE [38-40]. Furthermore, two additional absorption bands were found in 
the $1300-1000 \mathrm{~cm}^{-1}$ region, indicating the presence of $\mathrm{C}-\mathrm{O}$ groups, which is also typical for oxidative processes [38,39].



Figure 13. FTIR spectrum of the commercial LDPE film used to make the laminate, the LDPE regranulate, and the recycled film.

The thermal behavior of the virgin materialcompared with the recycled material was investigated by means of DSC measurements. The melting temperature in both cases was $109.74{ }^{\circ} \mathrm{C}$, which shows that there was no effect on the melting temperature and the crystallization temperature also remained constant, which was $100.89{ }^{\circ} \mathrm{C}$ for the virgin material and $101.08{ }^{\circ} \mathrm{C}$ for the recycled material. This observation is consistent with the expectations, as it is described in the literature that no significant differences can be observed between the melting and crystallization temperatures of multiextruded LDPE and untreated LDPE [26]. Jin et al. also describe that the percentage of crystallinity Xcr of the multiextruded LDPE remains basically constant for up to 40 extrusion cycles and only then starts to decrease [26]. In the present case, the degree of crystallinity of the PE starting film was $38.97 \%$, and that of the recycled film was $38.42 \%$. There was, therefore, a decrease of $1.41 \%$ in the degree of crystallinity, which was probably due to unavoidable differences in the evaluation. The DSC measurement curves of LDPE and the data obtained from them are given in the supporting information in Figure S3 and Table S1.

Figure 14 shows the influence of degassing/granulation and flat film extrusion on MFI and molecular weight. The literature reports that both chain scission and molecular enlargement occur simultaneously during thermal degradation of LDPE, but that crosslinking predominates over degradation, which is why extrusions lead to a decrease in MFI [26,41]. This is consistent with the values shown in Figure 14, where a decrease in MFI is observed after both regranulation and extrusion of the recycled film. However, the MFI decreases reported in the literature and also the value of the reference obtained by granulating the commercial LDPE film not treated with solvent are much stronger than for the recyclate. This indicates that the residual solvent hinders the crosslinking that normally occurs during extrusion. The reason for this could be that the solvent molecules increase the distance between the molecular chains, making crosslinking more difficult. The results of the SEC measurement confirm the conclusion that extrusion in the presence of the solvent leads to 
a much weaker increase in molecular weight. On the other hand, with the reference where no solvent is present, the molecular weight increases strongly. This is also reflected in an increase in the polydispersity index. For the samples extruded in the presence of solvent molecules, the polydispersity index does not change significantly, from which it can be concluded that the comparatively high MFIs of the delaminated material do not result from chain degradation.



Figure 14. Change in MFI and molecular weight after regranulation/cast film extrusion of the delaminated LDPE compared with the commercial LDPE film used to produce the laminate (virgin LDPE film) and the regranulated virgin film (reference).

Table 5 shows the results of tensile testing of the recycled film and the virgin LDPE film used for lamination parallel to the extrusion direction.

Table 5. Overview of the results of the tensile test of the recycled and the initial LDPE film.

\begin{tabular}{cccc}
\hline & Young Modulus Et & $\begin{array}{c}\text { Ultimate Tensile } \\
\text { Strength } \boldsymbol{\sigma} \mathbf{B}\end{array}$ & $\begin{array}{c}\text { Elongation at Break } \\
\in \mathbf{B}\end{array}$ \\
\hline $\mathbf{M P a}$ & $\mathbf{M P a}$ & $\mathbf{\%}$ \\
\hline Initial LDPE & $206 \pm 13.6$ & $31.3 \pm 1.56$ & $201.9 \pm 38.1$ \\
Recycled film & $133 \pm 12.8$ & $28.9 \pm 0.74$ & $244.1 \pm 26.0$ \\
\hline
\end{tabular}

It can be seen from the literature that due to crosslinking, an increase in tensile strength and ultimate tensile strength would be expected for recycled LDPE [39,42]. However, since the LDPE in the present case, as demonstrated by SEC, was only subjected to slight crosslinking, no increase in tensile strength could be observed. Instead, the measured sample exhibited a lower tensile strength and lower Young's modulus than the virgin film. The reason for this could be a plasticizing effect of the residual solvent. The increase in free volume between the polymer chains due to plasticizing molecule leads to deformation at lower forces, making the material less elastic and thus having a lower Young's modulus and also a lower tensile strength $[43,44]$. At the same time, the elongation of plasticized materials increases because the weakening of intermolecular interactions reduces the stiffness and increases the flexibility of the film [45-47]. The typical behavior of plasticized polymers also includes an increase in elongation. This tendency can also be observed in the present case, although the high standard deviation does not allow any concrete statement on this. However, it must be taken into account here that the commercial film has a thickness of 45-47 $\mu \mathrm{m}$, while the recycled film does not quite reach the target thickness of 
$45 \mu \mathrm{m}$ and is rather between $42-43 \mu \mathrm{m}$ thick. While this difference in thickness is taken into account in the tensile strength, this is not possible with elongation. With a film thickness of $45 \mu \mathrm{m}$ of the recycled film, an even higher value for the elongation would therefore be expected $[48,49]$.

The influence of the solvent on the quality of the LDPE can be reduced by reducing the solvent content prior to feeding into the extruder. This can be achieved by further optimizing the predrying or by carrying out an extraction of the solvent. The solvent content can also be further reduced by optimizing the degassing during granulation, thus further reducing its influence.

The properties of the recycled film should theoretically allow it to be used again in packaging applications. For food applications, it would first have to be checked whether the food law requirements can be met. According to EU Regulation 10/2011, this would involve guaranteeing that no more than $30 \mathrm{mg}$ of solvent can pass into $1 \mathrm{~kg}$ of food, which is why it may only be possible to use the film behind a functional barrier [50].

\subsubsection{Characterization of the Recovered PET}

The PET obtained was in the form of a predominantly transparent granule, which, however, exhibited a slight yellow coloration and also a whitish turbidity in some sections. Yellowing is more frequently observed in recycled PET and can be attributed to thermooxidative processes [51,52]. The whitish haze is due to residual LDPE that could not be removed during density separation. Since the melting point of LDPE is below that of PET, melt filtration is not possible in this case.

The influence of the recycling process on the molecular weight of PET is shown in Table 6 . Here, it can be seen that the solvent treatment and the predrying had no discernible influence on the molecular weight of the PET. During regranulation, however, a slight reduction in molecular weight took place. The determined weight-averaged molar mass of the regranulate was $36,653 \mathrm{~g} / \mathrm{mol}$ and thus just below the assumed error range of $10 \%$ of the starting material, which has a Mw of $41,564 \mathrm{~g} / \mathrm{mol}$.

Table 6. Influence of the individual recycling steps on the molecular weight of PET.

\begin{tabular}{cccc}
\hline Initial PET Film & $\begin{array}{c}\text { Delaminated } \\
\text { Material }\end{array}$ & Predried Material & Regranulated PET \\
\hline g/mol & $\mathbf{g} / \mathbf{m o l}$ & $\mathbf{g} / \mathbf{m o l}$ & $\mathbf{g} / \mathbf{m o l}$ \\
\hline $40,485 \pm 2025$ & $41,564 \pm 2078$ & $40,359 \pm 2018$ & $36,653 \pm 1833$ \\
\hline
\end{tabular}

It is well known that the Mw of PET often decreases during extrusion in recycling processes. In the case of pure PET, this can occur due to the presence of water in the form of hydrolytic chain scission or thermal chain scission [53]. One reason why only slight molar mass degradation occurred in the present case may be the thorough predrying of the material prior to extrusion or the maximum extrusion temperature of $260{ }^{\circ} \mathrm{C}$, which is lower than the temperature of $280^{\circ} \mathrm{C}$ usually mentioned as extrusion temperature for PET in the literature [53].

The spectrum of the regranulated PET shows some differences from the spectrum of the virgin material. For one thing, changes can be observed in the $\mathrm{C}-\mathrm{H}$ region between $3000-2800 \mathrm{~cm}^{-1}$. In the regranulate, two newly appeared bands at $2907 \mathrm{~cm}^{-1}$ and at 2853 $\mathrm{cm}^{-1}$ can be seen, which can be attributed to the LDPE content in the PET fraction. On the other hand, the other PE-typical bands at 1463 and $718 \mathrm{~cm}^{-1}$ are not found, probably because their intensity is lower and there are overlaps in the fingerprint region. The bands of PET in the $\mathrm{C}-\mathrm{H}$ region shift slightly and change their intensities, which can be attributed to either chain scissions, conformational changes, or both $[54,55]$. The bands with wavelengths $1470,1340,1118,970$, and $845 \mathrm{~cm}^{-1}$ significantly lost intensity somewhat, while the bands at 1370, 1044, and $898 \mathrm{~cm}^{-1}$ significantly gained intensity. These bands are characteristic of the trans or gauche rotational conformers of the ethylene glycol moiety in 
PET [55]. Since both conformers are found in the amorphous portion of the polymer, only the trans conformer is found in the crystalline phase. Since in the present case the absorption bands characteristic of the trans conformer decreased, this indicates that the regranulate has a higher amorphous fraction than the PET film used for laminate production. It is known from the literature that as a consequence of molar mass degradation during extrusion, an enrichment of trans conformers, and thus an increase in the overall degree of crystallinity, occurs [54-56]. Therefore, the increase in gauche content occurring in this case after the extrusion step must have a cause other than chain degradation. Another possible explanation could be that the crystallization of PET is disturbed by the contamination with LDPE. It has been reported in the literature that this is possible even though the two polymers are immiscible with each other [57].

However, this assumption can be ruled out on the basis of the DSC curves. The DSC measurement of the PET granulate shows that during the first heating process, a postcrystallization of the PET took place, which means that the conclusions drawn from the IR spectrum regarding the crystallinity were correct and the degree of crystallization of the regranulated PET was $13.91 \%$.

During the second heating run, however, no postcrystallization of the PET could be detected. The degree of crystallization determined from the measurement curve of the second heating process was $34.09 \%$, which was $2 \%$ higher compared with the degree of crystallinity of the virgin film, which was $33.21 \%$.

This means that the LDPE content did not hinder the crystallization of the PET in general, but that the cooling process during the production of the granulate prevented the crystallization. The fact that, in addition, the melt temperatures for both virgin and recycled material were $253.73{ }^{\circ} \mathrm{C}$ and $253.81^{\circ} \mathrm{C}$, respectively, shows that molar mass degradation has no effect on the thermal properties of PET. Additionally, it is worth mentioning that the LDPE content of the granulate is not visible in the DSC curve, which means that the LDPE content cannot crystallize. The DSC curves of the PET and the measurement data determined from them can be found in the Supplementary Information in Figures S4 and S5 and Table S2.

It should be possible to reduce the proportion of LDPE in PET using cyclonic separation, but it is nevertheless unlikely that the LDPE can be completely removed. Thus, in order to still be able to achieve good mechanical properties, the addition of compatibilizers might be necessary $[7,58]$. Such improved treatment or compatibilization of PET could then also lead to the possibility of reusing it in packaging applications. However, the food law restrictions already described for LDPE also apply here.

\section{Conclusions}

As multilayer packaging has a significant presence in the packaging market due to its versatile properties and advantages, its nonrecyclability is a highly discussed problem. However, if the individual materials are bonded with a reversibly crosslinking adhesive, the packaging can be separated into its individual components, and these can then be recycled individually.

Since this concept has so far only been pursued on a laboratory scale, this work shows that upscaling of laminate production to a pilot plant for lacquering and lamination and delamination and subsequent recycling of the laminate on a small-scale technical plant are possible. The generated bond adhesion of the laminate is $>4 \mathrm{~N} / 15 \mathrm{~mm}$ and is so good that there is substrate failure of the PET film when performing the T-peel test. Delamination of the composite and subsequent further processing made it possible to produce PET and LDPE regranulate, and the LDPE regranulate was also used to produce a recycled film. The characterization of the material shows good properties of LDPE and suitability for reapplication as film. In order to ensure high-quality reuse of the PET, the residual LDPE content in this fraction would have to be achieved, for example, by means of adapted density separation (e.g., by cyclonic separation), or the addition of a compatibilizer would have to be considered. By optimizing these process steps and extending this principle to 
other packaging laminates, a future model for recycling multilayer packaging and thus increasing recycling rates could be developed.

Supplementary Materials: The following are available online at https:/ /www.mdpi.com/article/10 $.3390 /$ recycling6030047/s1: Figure S1: Comparison of the ring deformation band of the maleimide group at $696 \mathrm{~cm}^{-1}$ of the cured adhesive exposed to $160{ }^{\circ} \mathrm{C}$ for $1 \mathrm{~s}$ and the cured/uncured adhesive. Figure S2: Comparison of the ring deformation band of the maleimide group at $696 \mathrm{~cm}^{-1}$ from the cured adhesive exposed to $105{ }^{\circ} \mathrm{C}$ for $20 \mathrm{~min}$ and the cured/uncured adhesive. Figure S3: DSC curve of the initial PE film (green) and recycled PE film (blue). Figure S4: DSC curve of initial PET film (blue) and regranulated PET (green). Figure S5: DSC curves of the recycled PET. Shown are the first heating run in black, the cooling curve in red, and the second heating run in blue. Table S1: Data from DSC evaluation of initial PE film and recycled PE film. Table S2: Data from DSC evaluation of initial PET film and reganulated PET.

Author Contributions: K.M.A.K. planned and carried out the polymer syntheses and planned and supervised the lamination and the recycling of the laminate. She also conceived and wrote the manuscript. T.G. organized the drying of the delaminated films and the extrusion of the materials. Both authors have read and agreed to the published version of the manuscript.

Funding: This research received no external funding.

Institutional Review Board Statement: Not applicable.

Informed Consent Statement: Not applicable.

Data Availability Statement: The data presented in this study are available in supplementary material.

Acknowledgments: Special thanks goes to Morchem S.A., especially to Cristina Ventayol, which provided isocyanate prepolymers for the production the furfurylamine-functionalized prepolymer. Additionally, many thanks goes to Petra Treppe and the Polymer Separation Group at the LeibnizInstitut für Polymerforschung Dresden e.V./Stellenbosch University for the HT-SEC measurements of LDPE. Thanks goes also to Norbert Rodler and the technical team members of the Materials Development for their support with the laminate production and the technical team of the Recycling Department for their support with the recycling of the laminate. We also thank David Bauer for performing GPC and HS-GC measurements and Kerstin Müller for proofreading.

Conflicts of Interest: The authors declare no conflict of interest.

\section{References}

1. Wagner, J.R. (Ed.) Multilayer Flexible Packaging, 2nd ed.; William Andrew is an imprint of Elsevier: Oxford, UK, 2016; ISBN 9780323371001.

2. Morris, B.A. The Science and Technology of Flexible Packaging: Multilayer Films from Resin and Process to End Use; Elsevier Ltd: Oxford, UK, 2017; ISBN 0323243258.

3. Kaiser, K.; Schmid, M.; Schlummer, M. Recycling of Polymer-Based Multilayer Packaging: A Review. Recycling $2018,3,1$. [CrossRef]

4. European Commisson. A European Strategy for Plastics in a Circular Economy; Brussels, Belgium, 2018. Available online: https: // www.oneplanetnetwork.org/initiative/european-strategy-plastics-circular-economy (accessed on 12 July 2021).

5. Benhamida, A.; Kaci, M.; Cimmino, S.; Silvestre, C.; Duraccio, D. Evaluation of the Effectiveness of New Compatibilizers Based on EBAGMA-LDPE and EBAGMA-PET Masterbatches for LDPE/PET Blends. Macromol. Mater. Eng. 2010, 295, 222-232. [CrossRef]

6. Martínez, J.G.; Benavides, R.; Guerrero, C. Polyethylenes/PET blend compatibilization with maleic anhydride modified polyethylenes obtained by a UV preirradiation process. J. Appl. Polym. Sci. 2007, 104, 560-567. [CrossRef]

7. Zhang, Y.; Zhang, H.; Guo, W.; Wu, C. Effects of different types of polyethylene on the morphology and properties of recycled poly(ethylene terephthalate)/polyethylene compatibilized blends. Polym. Adv. Technol. 2011, 22, 1851-1858. [CrossRef]

8. Araujo, L.M.G.; Morales, A.R. Compatibilization of recycled polypropylene and recycled poly (ethylene terephthalate) blends with SEBS-g-MA. Polimeros 2018, 28, 84-91. [CrossRef]

9. Benzing, K.; Fleig, J.; Feiss, D.; Rott, H. Separating Aluminum-Containing Composites, Eg For Recycling Packaging Materials, Involves Treatment with Alkali Solution to Dissolve Aluminum and Precipitate Other Materials. DE10102554, 19 January 2002.

10. Chui, Y.; Lee, M.; Kim, H. A Recycling Method of Multilayer Packaging Film Waste. EP1683829A1, 26 July 2006.

11. Samorì, C.; Cespi, D.; Blair, P.; Galletti, P.; Malferrari, D.; Passarini, F.; Vassura, I.; Tagliavini, E. Application of switchable hydrophilicity solvents for recycling multilayer packaging materials. Green Chem. 2017, 19, 1714-1720. [CrossRef]

12. Cinelli, P.; Schmid, M.; Bugnicourt, E.; Coltelli, M.B.; Lazzeri, A. Recyclability of PET/WPI/PE Multilayer Films by Removal of Whey Protein Isolate-Based Coatings with Enzymatic Detergents. Materials 2016, 9, 473. [CrossRef] [PubMed] 
13. Banea, M.D. Debonding on Demand of Adhesively Bonded Joints. In Progress in Adhesion and Adhesives; Mittal, K.L., Ed.; Scrivener: Hoboken, NJ, USA, 2020; pp. 33-50; ISBN 9781119749882.

14. Sanyal, A. Diels-Alder Cycloaddition-Cycloreversion: A Powerful Combo in Materials Design. Macromol. Chem. Phys. 2010, 211, 1417-1425. [CrossRef]

15. Gandini, A. The furan/maleimide Diels-Alder reaction: A versatile click-unclick tool in macromolecular synthesis. Prog. Polym. Sci. 2013, 38, 1-29. [CrossRef]

16. Khan, N.I.; Halder, S.; Gunjan, S.B.; Prasad, T. A review on Diels-Alder based self-healing polymer composites. IOP Conf. Ser. Mater. Sci. Eng. 2018, 377, 12007. [CrossRef]

17. Carneiro de Oliveira, J.; Laborie, M.-P.; Roucoules, V. Thermodynamic and Kinetic Study of Diels-Alder Reaction between Furfuryl Alcohol and N-Hydroxymaleimides-An Assessment for Materials Application. Molecules 2020, 25, 243. [CrossRef]

18. Kaiser, K.M.A. Recycling of multilayer packaging using a reversible cross-linking adhesive. J. Appl. Polym. Sci. 2020, 137, 49230. [CrossRef]

19. Kaiser, K.M.A.; Ewender, J.; Welle, F. Recyclable Multilayer Packaging by Means of Thermoreversibly Crosslinking Adhesive in the Context of Food Law. Polymers 2020, 12, 2988. [CrossRef] [PubMed]

20. GVM Gesellschaft für Verpackungsmarkforschung. Flexible Plastic Packaging Market in Germany and in Europe: Trends and Perspectives until 2021 by Product Categories; GVM Gesellschaft für Verpackungsmarkforschung: Mainz, Germany, 2017.

21. Heo, Y.; Sodano, H.A. Self-Healing Polyurethanes with Shape Recovery. Adv. Funct. Mater. 2014, 24, 5261-5268. [CrossRef]

22. Duan, H.-Y.; Wang, Y.-X.; Wang, L.-J.; Min, Y.-Q.; Zhang, X.-H.; Du, B.-Y. An Investigation of the Selective Chain Scission at Centered Diels-Alder Mechanophore under Ultrasonication. Macromolecules 2017, 50, 1353-1361. [CrossRef]

23. Du, P.; Wu, M.; Liu, X.; Zheng, Z.; Wang, X.; Sun, P.; Joncheray, T.; Zhang, Y. Synthesis of linear polyurethane bearing pendant furan and cross-linked healable polyurethane containing Diels-Alder bonds. New J. Chem. 2014, 38, 770-776. [CrossRef]

24. Friedhelm Gores, P.K. Tips \& Tricks: GPC/SEC: Examining accuracy and precision in GPC/SEC. Column 2008, 2, 20-23.

25. Dostál, J.; Kašpárková, V.; Zatloukal, M.; Muras, J.; Šimek, L. Influence of the repeated extrusion on the degradation of polyethylene. Structural changes in low density polyethylene. Eur. Polym. J. 2008, 44, 2652-2658. [CrossRef]

26. Jin, H.; Gonzalez-Gutierrez, J.; Oblak, P.; Zupančič, B.; Emri, I. The effect of extensive mechanical recycling on the properties of low density polyethylene. Polym. Degrad. Stab. 2012, 97, 2262-2272. [CrossRef]

27. Mieth, A.; Hoekstra, E.; Simoneau, C. Guidance for the Identification of Polymers in Multilayer Films Used in Food Contact Materials: User Guide of Selected Practices to Determine the Nature of Layers; Publications Office of the EU: Luxembourg, Luxembourg, 2016.

28. Turkenburg, D.H.; van Bracht, H.; Funke, B.; Schmider, M.; Janke, D.; Fischer, H.R. Polyurethane adhesives containing DielsAlder-based thermoreversible bonds. J. Appl. Polym. Sci. 2017, 134. [CrossRef]

29. Planes, E.; Marouani, S.; Flandin, L. Optimizing the heat sealing parameters of multilayers polymeric films. J. Mater. Sci. 2011, 46, 5948-5958. [CrossRef]

30. Scutaru, A.M.; Wenzel, M.; Gust, R. Bivalent bendamustine and melphalan derivatives as anticancer agents. Eur. J. Med. Chem. 2011, 46, 1604-1615. [CrossRef]

31. Bai, N.; Saito, K.; Simon, G.P. Synthesis of a diamine cross-linker containing Diels-Alder adducts to produce self-healing thermosetting epoxy polymer from a widely used epoxy monomer. Polym. Chem. 2013, 4, 724-730. [CrossRef]

32. Otto, S.; Blokzijl, W.; Engberts, J.B.F.N. Diels-Alder Reactions in Water. Effects of Hydrophobicity and Hydrogen Bonding. J. Org. Chem. 1994, 59, 5372-5376. [CrossRef]

33. Yadav, V.K.; Prasad, D.L.V.K.; Yadav, A.; Yadav, K. On the solvent- and temperature-driven stereoselectivity of the Diels-Alder cycloaddition reactions of furan with maleic anhydride and maleimide. J. Phys. Org. Chem. 2021, 34. [CrossRef]

34. Froidevaux, V.; Borne, M.; Laborbe, E.; Auvergne, R.; Gandini, A.; Boutevin, B. Study of the Diels-Alder and retro-Diels-Alder reaction between furan derivatives and maleimide for the creation of new materials. RSC Adv. 2015, 5, 37742-37754. [CrossRef]

35. Ruiz-Lopez, M.F.; Assfeld, X.; Garcia, J.I.; Mayoral, J.A.; Salvatella, L. Solvent effects on the mechanism and selectivities of asymmetric Diels-Alder reactions. J. Am. Chem. Soc. 1993, 115, 8780-8787. [CrossRef]

36. Widstrom, A.L.; Lear, B.J. Structural and solvent control over activation parameters for a pair of retro Diels-Alder reactions. Sci. Rep. 2019, 9, 18267. [CrossRef] [PubMed]

37. Scholte, T.G.; Meijerink, N.L.J. Gel permeation chromatography on branched polymers. Brit. Poly. J. 1977, 9, 133-139. [CrossRef]

38. Gaston, F.; Dupuy, N.; Marque, S.R.A.; Barbaroux, M.; Dorey, S. One year monitoring by FTIR of $\gamma$-irradiated multilayer film PE/EVOH/PE. Radiat. Phys. Chem. 2016, 125, 115-121. [CrossRef]

39. Czarnecka-Komorowska, D.; Wiszumirska, K.; Garbacz, T. Films ldpe/lldpe made from post—Consumer plastics: Processing, structure, mechanical properties. Adv. Sci. Technol. Res. J. 2018, 12, 134-142. [CrossRef]

40. Almond, J.; Sugumaar, P.; Wenzel, M.N.; Hill, G.; Wallis, C. Determination of the carbonyl index of polyethylene and polypropylene using specified area under band methodology with ATR-FTIR spectroscopy. Polymers 2020, 20, 369-381. [CrossRef]

41. Yin, S.; Tuladhar, R.; Shi, F.; Shanks, R.A.; Combe, M.; Collister, T. Mechanical reprocessing of polyolefin waste: A review. Polym. Eng. Sci. 2015, 55, 2899-2909. [CrossRef]

42. Mendes, A.A.; Cunha, A.M.; Bernardo, C.A. Study of the degradation mechanisms of polyethylene during reprocessing. Polym. Degrad. Stab. 2011, 96, 1125-1133. [CrossRef]

43. Lim, H.; Hoag, S.W. Plasticizer effects on physical-mechanical properties of solvent cast Soluplus@films. AAPS PharmSciTech 2013, 14, 903-910. [CrossRef] [PubMed] 
44. Sanyang, M.; Sapuan, S.; Jawaid, M.; Ishak, M.; Sahari, J. Effect of Plasticizer Type and Concentration on Tensile, Thermal and Barrier Properties of Biodegradable Films Based on Sugar Palm (Arenga pinnata) Starch. Polymers 2015, 7, 1106. [CrossRef]

45. Jantrawut, P.; Chaiwarit, T.; Jantanasakulwong, K.; Brachais, C.H.; Chambin, O. Effect of Plasticizer Type on Tensile Property and In Vitro Indomethacin Release of Thin Films Based on Low-Methoxyl Pectin. Polymers 2017, 9, 289. [CrossRef]

46. Fishman, M.L.; Coffin, D.R.; Konstance, R.P.; Onwulata, C.I. Extrusion of pectin/starch blends plasticized with glycerol. Carbohydr. Polym. 2000, 41, 317-325. [CrossRef]

47. Muscat, D.; Adhikari, B.; Adhikari, R.; Chaudhary, D.S. Comparative study of film forming behaviour of low and high amylose starches using glycerol and xylitol as plasticizers. J. Food Eng. 2012, 109, 189-201. [CrossRef]

48. West, S. The Effect of Process Parameters on the Mechanical and Optical Properties of Cast Film; McMaster University: Hamilton ON, Canada, 2005.

49. Macauley, N.J.; Harkin-Jones, E.M.A.; Murphy, W.R. The influence of extrusion parameters on the mechanical properties of polypropylene sheet. Polym. Eng. Sci. 1998, 38, 662-673. [CrossRef]

50. The European Commission. Commission Regulation (EU) No 10/2011: Of 14 January 2011 on Plastic Materials and Articles Intended to Come into Contact with Food; Brussels, Belgium, 2011; Available online: https:/ / eur-lex.europa.eu/legal-content/EN/TXT/?uri= celex:32011R0010 (accessed on 12 July 2021).

51. Berg, D.; Schaefer, K.; Koerner, A.; Kaufmann, R.; Tillmann, W.; Moeller, M. Reasons for the Discoloration of Postconsumer Poly(ethylene terephthalate) during Reprocessing. Macromol. Mater. Eng. 2016, 301, 1454-1467. [CrossRef]

52. Ladasiu Ciolacu, C.F.; Roy Choudhury, N.; Dutta, N.K. Colour formation in poly(ethylene terephthalate) during melt processing. Polym. Degrad. Stab. 2006, 91, 875-885. [CrossRef]

53. Awaja, F.; Pavel, D. Recycling of PET. Eur. Polym. J. 2005, 41, 1453-1477. [CrossRef]

54. Sammon, C.; Yarwood, J.; Everall, N. An FT-IR study of the effect of hydrolytic degradation on the structure of thin PET films. Polym. Degrad. Stab. 2000, 67, 149-158. [CrossRef]

55. López, M.d.M.C.; Ares Pernas, A.I.; Abad López, M.J.; Latorre, A.L.; López Vilariño, J.M.; González Rodríguez, M.V. Assessing changes on poly(ethylene terephthalate) properties after recycling: Mechanical recycling in laboratory versus postconsumer recycled material. Mater. Chem. Phys. 2014, 147, 884-894. [CrossRef]

56. Donelli, I.; Taddei, P.; Smet, P.F.; Poelman, D.; Nierstrasz, V.A.; Freddi, G. Enzymatic surface modification and functionalization of PET: A water contact angle, FTIR, and fluorescence spectroscopy study. Biotechnol. Bioeng. 2009, 103, 845-856. [CrossRef] [PubMed]

57. Pracella, M. Crystallization of Polymer Blends. In Handbook of Polymer Crystallization; Piorkowska, E., Rutledge, G.C., Eds.; Wiley: Hoboken, NJ, USA, 2013; pp. 287-326. ISBN 9781118541838.

58. Delva, L.; Deceur, C.; van Damme, N.; Ragaert, K. Compatibilization of PET-PE blends for the recycling of multilayer packaging foils. In Proceedings of the Europe/Africa Conference Dresden 2017-Polymer Processing Society PPS, Dresden, Germany, 27-29 June 2017; p. 30005. 